\title{
Destination Choice Modeling for Home-Based Recreational Trips; Analysis and Implications for Land-Use, Transportation, and Air Quality Planning
}

\author{
Michael A. Pozsgay and Chandra R. Bhat \\ Department of Civil Engineering, The University of Texas at Austin \\ ECJ 6.810, Tel: (512) 471-4535, Fax: (512) 475-8744 \\ E-mail:pozsgay@mail.utexas.edu,bhat@mail.utexas.edu
}

\begin{abstract}
Attraction-end choice studies have primarily focused on non-urban recreational trips or non-recreational urban trips. Relatively little attention has been focused in the literature on urban recreational trips. In contrast, urban recreation trips are contributing increasingly to overall urban travel. In this paper, we examine attraction-end choice models for home-based urban recreational trips. A non-linear-in-parameters multinomial logit model is estimated using the 1996 Dallas-Fort Worth household activity survey. The effects of level-of-service, zonal attributes, trip attributes, and socio-demographic variables on recreational attraction-end choice are examined, and the implications of the results for land-use, transportation planning, and air quality analysis are discussed.
\end{abstract}




\section{INTRODUCTION}

Traffic congestion resulting from participation in recreational activities such as sporting events, concerts, and festivals are a frequent occurrence in many metropolitan areas. According to the 1990 Nationwide Personal Transportation Survey (NPTS), recreational trips constitute about $12 \%$ of all urban trips on weekdays. This percentage rises to about $23 \%$ on weekends, when more recreational trips are pursued. The NPTS data also indicates that the average recreational trip length is around 13 miles, over twice the length of the average shopping trip. In addition, recreational trips are primarily pursued using the private automobile (Steed and Bhat [1]). As a result of these factors, urban recreational travel contributes a significant number of passenger vehicle miles of travel on urban streets today. This contribution is only likely to grow in the future as leisure time and disposable income increase in the United States (U.S. Dept. of Commerce [2]), and as the socio-demographic characteristics of the population change over time (Misra and Bhat [3]).

In contrast to the significant current (and projected) contributions of recreational travel to overall urban travel, relatively little attention has been focused on recreational activity participation in travel modeling practice. Most metropolitan areas still continue to use a trip purpose classification that groups all non-work trips into a single category for modeling purposes; in fact, the emphasis in many metropolitan areas continues to be on work trips. However, many recent studies (Handy [4]; Hunt [5]; Bhat [6]) have underscored the need to model non-work trips more systematically and to recognize the behavioral differences underlying travel decisions for different types of non-work trips. The broad objective of this paper is to contribute toward this growing literature on non- 
work trip modeling, with a specific focus on home-based urban recreational trips. We limit our attention to the destination (or, more precisely, attraction-end) choice dimension of recreational travel in this paper, because other dimensions of choice in the context of recreational trips such as number of trips, mode choice, and departure time have been examined elsewhere (Steed and Bhat [1]; Bhat [6]; Hunt [5]; Kumar and Levinson [7]). Another reason for our focus on attraction-end choice modeling is that disaggregate analysis procedures (that is, methods that examine travel choices at the level of the decision-making unit such as the individual or the household) have yet to influence the fundamental specification of trip attraction and distribution models employed in practice; in particular, most MPOs still use aggregate-level cross-classification and gravity models, which do not adequately account for the characteristics of households and trip makers, and the way in which those characteristics interact with the attributes of alternative destinations (in an exhaustive review of travel demand modeling practice in several metropolitan planning organizations in the country, (Deakin, Harvey, Skabardonis, Inc. [8]) indicated that "the aggregate gravity model remains deeply ingrained in practice despite its apparent disadvantages").

There are several potential benefits from improving our ability to predict recreational attraction-end choice of individuals as a function of their socio-demographic attributes and the interaction of these attributes with level-of-service and destination characteristics. First, a disaggregate attraction-end recreational choice model would facilitate improved policy evaluation of transportation control measures (TCMs) as well as better forecasting of travel conditions because it can accommodate the effect of multiple level-of-service measures, and allow variations in sensitivity to level-of-service measures and attraction- 
end characteristics across different socio-demographic sub-groups. Second, improved attraction-end choice modeling of recreational trips would contribute to more accurate estimates of vehicle trip lengths and, therefore, better estimates of vehicle miles of travel (VMT). This, in turn, would facilitate improved air quality modeling, since VMT is a critical input to mobile-source emissions forecasting. Third, improved recreational attraction-end modeling could facilitate land-use planning that is directed toward locating recreational facilities to reduce VMT or to improve accessibility to recreational facilities for mobility-challenged sub-groups of the population (see Williams [9] for an extensive discussion of this issue).

The literature in the area of attraction end choice research is rather sparse in the context of urban recreational travel. Previous attraction-end choice studies have focused primarily on urban work and shopping trips (see, for example, Timmermans [10], Miller and O'Kelly [11], Bhat, et al. [12], Koppelman and Hauser [13], and Eash [14]). The few recreational attraction-end choice studies that have been undertaken focus on longdistance, inter-city, trips (see, for example, Train [15], Morey, et al. [16], and Yai, et al. [17]). The current paper, on the other hand, examines attraction-end choice for urban recreational travel.

The remainder of this paper is structured as follows. Section 2 develops the model formulation. Section 3 presents the data sources used in the empirical analysis of the paper and discusses data assembly procedures. Section 4 presents the empirical results. The final section summarizes the important findings from the study and highlights the implications of the findings for land-use, transportation and air quality planning. 


\section{MODEL FORMULATION}

This section discusses the spatial unit used to define attraction-end alternatives (Section 2.1), presents the procedure used to generate the attraction-end alternatives in each individual's choice set (Section 2.2), and finally develops the model formulation used in the analysis (Section 2.3).

\subsection{Definition of Attraction-End Choice Alternatives}

The disaggregate attraction-end choice model predicts the individual choice of travel to aggregated zones (or spatial clusters) and not to specific recreational sites within the zones (or elemental alternatives). We adopt this approach for two reasons. First, the use of elemental alternatives would create a substantial number of alternatives in the individual's choice set. This would pose infeasible data processing requirements, and make the modeling process and definition of alternatives difficult. $\underline{\text { Second, for }}$ transportation planning, the desired end-result is the prediction of trip-interchanges between zonal pairs, not between elemental attraction alternatives. From this standpoint, an attraction-end choice model with zonal alternatives is easy to apply for forecasting.

\subsection{Generation of Alternatives in the Choice Set}

The number of possible attraction-end alternatives for a trip is very large, even after defining alternatives at the zonal level. To resolve this situation, we draw a subset of alternatives from the universal choice set for each trip. Restricting the number of alternatives in this manner is acceptable as long as an identically and independently distributed (IID) structure is assumed for the random error terms across attraction-end 
alternatives (McFadden [18]). This is the error structure we adopt in our model, as discussed in the next section.

There are several approaches to drawing the subset of alternatives from the universal choice set (see Ben-Akiva, et al. [19]). The simplest approach is to select a subset of nonchosen alternatives randomly from the universal choice set, and then add the chosen alternative to this subset. We use this approach in the current paper to generate a choice set with ten alternatives for each trip, nine of which are randomly picked non-chosen alternatives and the tenth is the actual chosen alternative.

\subsection{Model Structure}

The alternatives in the attraction-end model are aggregated zones. Each zone $j$ may contain several possible elemental attraction alternatives. Let the number of elemental attractions in $j$ be $D_{j}$. Assume the following: a) $D_{j}$ is large for each zone, b) utilities of the elemental alternatives within each zone are IID, and c) the quality of elemental attraction alternatives are relatively homogenous within each aggregate zone or the within-zone variance of the systematic utilities of the elemental alternatives are about equal across zones. With these assumptions, the utility $U_{q i j}$ accruing to an individual $q$ in zone $i$ from choosing attraction-end zone $j$ may be written as (see Daly [20]):

$$
U_{q i j}=V_{q i j}+\varepsilon_{q i j}=\beta^{\prime} x_{q i j}+\gamma \log \left(D_{j}\right)+\varepsilon_{q i j}
$$

where $x_{q i j}$ is a vector of exogenous variables influencing the choice of zone $j$ for an individual $q$ in zone $i, D_{j}$ is the number of elemental attractions in attraction-end zone $j$, and $\varepsilon_{q i j}$ is a random term distributed IID gumbel across zonal alternatives and individuals. $\beta$ is a vector and $\gamma$ is a scalar, both of which are to be estimated. The number of elemental 
attractions within a zone, $D_{j}$, is not easily quantifiable. However, we can proxy $D_{j}$ by a set of observable size variables of zone $j$, such as total area of the zone or areas in different types of land-uses. Let $d_{j}$ represent a vector of proxy size variables for zone $j$ and let $\delta$ be a corresponding vector reflecting the contribution of the proxy size variables to the actual zone size $D_{j}$. Then, we re-write equation (1) as:

$$
U_{q i j}=V_{q i j}+\varepsilon_{q i j}=\beta^{\prime} x_{q i j}+\gamma \log \left(\delta^{\prime} d_{j}\right)+\varepsilon_{q i j}
$$

The magnitude of the "logsum" parameter $\gamma$ represents the presence of common unobserved zonal attributes affecting the attractiveness of elemental alternatives in a zone. If there are no common unobserved factors influencing the attractiveness of elemental alternatives within a zone, the parameter equals one. On the other hand, if all unobserved factors affecting the attractiveness of elemental alternatives are unobserved zonal attributes, the parameter equals zero. In practice, we would expect the value of $\gamma$ to fall between 0 and 1 .

The probability that individual $q$ will choose attraction-end $j$ from the choice set $C_{q}$ may be computed from equation (2) and the assumed IID distribution of the random components:

$$
P_{q i j}=\frac{e^{V_{q i j}}}{\sum_{j^{\prime} \in C_{q}} e^{V_{q i j^{\prime}}}}
$$

The model specified above is similar to the familiar multinomial logit model. However, it differs due to the presence of the component $\gamma \log \left(\delta^{\prime} d_{j}\right)$ in equation (2), which implies a non-linear (in parameters) utility function. The model is estimated using a maximum likelihood procedure written in the GUASS matrix programming language. 


\section{DATA SOURCE AND ASSEMBLY}

\subsection{Data Sources}

Three data sources are used in this research, all of which were obtained from the North Central Council of Governments (NCTCOG) in the Dallas-Fort Worth area. The first data source is the 1996 Dallas-Fort Worth metropolitan area household activity survey. This survey collected information about travel and non-travel activities undertaken during a weekday by members of 4839 households. The survey also obtained individual and household socio-demographic information.

The second data source is a level-of-service (LOS) file that provides information on travel between each pair of the 919 Transportation Analysis Process (TAP) zones in the Dallas-Fort Worth area. The file contains peak and off-peak level-of-service information (including travel times, distances and costs) for transit and highway modes.

The third data source is a zonal-level land use characteristics file containing land use data at the level of the traffic survey zone (TSZ) within the Dallas-Fort Worth metropolitan planning area. The land use information for each TSZ provides information on total land area and acreage in several disaggregate land use purposes (for example, park space, business, public utility, retail and water).

\subsection{Data Assembly}

The objective of data assembly was to extract the home-based recreational trips from the activity survey and structure the data in a form suitable for estimation. Several steps were involved in this process. The first step separated the travel records (trips) in the survey from the non-travel records (activities). The purpose of each trip was identified 
from the activities preceding and following the trip. The TAP zones of the production and attraction end of each trip were also identified and retained. All non-traveling entries were deleted from the dataset.

The second step selected home-based recreational trips from the set of all trips. The original dataset includes thirty-six codes for activity type. Three of these codes describe various types of recreational trips: health club, exercise / recreation, and entertainment. Records with these codes for the origin or destination purpose were flagged as recreational trips. Five activity codes in the survey represented home activities. A record containing any of these as their origin or destination purpose was flagged as home-based. Finally, records that were flagged as both recreational and home-based were selected, and the remaining records were discarded.

The third step converted variables in the activity survey to more useful representations for analysis. This step included extracting the age of each individual from the birth date, obtaining the number of children in the household in each of several age categories, and creating dummy variables for race, education, sex, and employment status.

The fourth step randomly selected nine alternative attraction TAP zones for each trip (not including the actual selected attraction zone) and then added the actual chosen attraction zone (for a total of ten attraction-end alternatives). Next, each recreational trip production was replicated ten times and each attraction-end alternative generated earlier was appended to one of the ten replicated records. A variable indicating the actual chosen attraction-end zone of the ten alternatives was created. 
The fifth step appended the appropriate zone-to-zone level-of-service (LOS) values from the zonal LOS file to each of the ten records of each trip in the replicated file based on the production-end TAP zone and attraction-end TAP zone. The LOS variables in the zonal LOS file include distance, cost, in-vehicle travel time (IVTT) and out-of-vehicle travel time (OVTT); the values for these variables differ by time-of-day and travel mode. The LOS values appended to each record corresponded to the time-of-day of the trip and the mode (drive alone or shared-ride) used for the trip.

The sixth step aggregated the TSZ-level land-use and demographic characteristics to the TAP-level, and appended this information to each trip record based on the TAP identifier of the attraction-end zone.

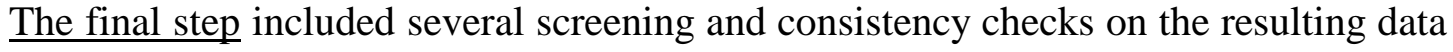
set from the previous steps (a flow chart of this screening process is available from the authors).

The final sample file for analysis includes 777 trip cases $(777 \times 10=7770$ records $)$. All of these recreational trips are pursued using some form of motorized personal transportation (car, van, truck or motorcycle). No home-based recreational trips in the sample were pursued using transit. About 54\% of recreational trips are pursued alone, while $46 \%$ represent joint participation.

\section{EMPIRICAL ANALYSIS}

\subsection{Variable Specification}

Several types of variables were considered for the recreational attraction-end choice model. These include a) travel impedance characteristics, b) attraction-end zone 
attributes, c) an attraction-end zonal spatial structure measure, d) trip characteristics, and e) interactions of individual and household characteristics with the preceding four sets of variables. Each of these sets of variables is discussed next.

The travel impedance characteristics considered in our analysis included the cost, invehicle travel time (IVTT) and out-of-vehicle travel time (OVTT). The cost variable is a summation of per-mile travel costs, parking costs and toll costs of a trip. Due to substantial multi-collinearity among the impedance measures, we converted cost and OVTT into equivalent IVTT units using money values of time obtained from travel mode choice estimation. Thus, travel impedance is incorporated as a single comprehensive measure in effective IVTT units. We considered two functional forms for the effect of the composite impedance variable on utility; the linear form and the log-linear form (these are the two most widely used forms in the literature; see Fotheringham [21]). The linear form implies that the marginal deterrence due to travel impedance is independent of the existing impedance level, while the log-linear form implies that the marginal deterrence decreases as the existing travel impedance level increases (that is, a constant increase in the composite impedance has a higher deterrence when the initial impedance level is low than when the initial impedance level is high). Between the linear and log-linear functional forms, we found the log-linear form to perform substantially better in the empirical analysis and, therefore, retained this functional form for the composite impedance variable.

The attraction-end zone attributes included size variables and non-size variables. Several size variables, representing acreages in different kinds of land uses (such as park space, retail space, water area, etc.), were considered in the analysis. As indicated in 
Section 2, these land use acreages may be considered as substitute measures for the amount of recreational opportunity within a zone. Non-size variables associated with the zones were also considered in the analysis.

The zonal spatial measure was created to capture the impact of the location pattern of recreational attraction-end zones. Consider the following simple example drawn from Fotheringham [21]. Let an individual in zone $i$ have a choice of 5 alternative attractionend zones for her/his recreational trip. The five alternatives are equivalent in all respects, including in size and impedance from zone $i$. Now, consider two alternative spatial arrangements of the zones as shown in Figure 1. It is possible that the individual's choice of zone 1 in the two spatial arrangements is different. One possibility is that zone 1 is more attractive in the first configuration than the second because of competition effects; that is, zone 1 may occupy a unique location in the spatial cognitive perception of the individual in zone $i$ because it is isolated, while there is more competition among other potential attraction zones (zones 2 through 5). In addition, zone 1 may be preferred in arrangement 1 because of higher traffic congestion in and around a group of zones with several complementary recreational opportunities in close proximity. On the other hand, zone 1 may be more attractive in the second configuration than the first because of what Fotheringham labels as an agglomeration effect; that is, individuals in zone $i$ may perceive a greater variety of recreational opportunities in zone 1 in the second configuration because of the clustered nature of recreational opportunities. We develop a zonal spatial measure to capture these spatial location pattern effects. Because several land use types are important in recreation attraction-end choice, we created spatial 
measures specific to three land use types: water, parkland and retail. These measures are created using the following formulation adopted by Bhat, et al. [12]:

$$
M_{j}=\left[\frac{1}{L} \sum_{l=1}^{L}\left(\frac{\log R_{l}}{\log H_{l j}}\right)\right]
$$

In the above equation, $M_{j}$ is the spatial measure for attraction-end zone $j, R_{l}$ is the acreage in a particular type of land use within zone $l, H_{l j}$ is the travel impedance between zones $l$ and $j$, and $L$ is the total number of TAP zones in the Dallas-Fort Worth region. The spatial measure for an attraction-end zone is higher if there are a large number of recreational opportunities in the immediate vicinity of that zone, and is lower if the zone is spatially isolated from other recreational opportunities. Hence, a positive coefficient on the spatial structure measure in estimation would suggest that travelers prefer clustering of recreational opportunities (that is, agglomeration effects dominate and zone 1 is more attractive in the first spatial configuration than in the second in Figure 1); conversely, a negative coefficient would suggest that travelers prefer zones that are spatially isolated (that is, competition effects dominate and zone 1 is more attractive in the second arrangement than in the first in Figure 1).

The trip related attributes describe the recreational excursion. Several trip-related variables (including number of individuals participating in the recreational pursuit, travel mode choice, and departure time of trip) were considered in the analysis.

The final set of variables comprises interaction effects of individual and household socio-demographics with other sets of variables. The motivation for considering such interaction effects is that the sensitivity to travel impedance, or to zonal size and non-size measures, or to the zonal spatial measure may vary across socio-demographic sub- 
groups. For example, older individuals may be more sensitive to travel impedance than younger individuals because of greater mobility challenges. Similarly, households with children may be more sensitive to travel impedance since they might want to invest in less travel time and more recreational time at the destination. Also, the sensitivity to travel impedance may vary based on the income of the household.

\subsection{Empirical Results}

The final specification results of the home-based recreational attraction-end choice model are presented in Table 1. The log-likelihood value at convergence is -876.70 , the log-likelihood value with no variables in the model is -1789.00 , and the loglikelihood value with only the impedance variable and the size variable is -935.61 (the size variable in this last model is represented as retail acreage $+0.0458 *$ other acreage; the coefficient of 0.0458 is borrowed from the convergent value in our attraction-end choice model). The latter log-likelihood value corresponds to a model that is the disaggregate equivalent of the traditional production-constrained gravity model with a parametric power function for the effect of travel impedance (see Deakin, Harvey, Skabardonis, Inc. [8]). The log-likelihood ratio test value for comparing the attraction-end choice model with the disaggregate form of the gravity model is 118 . This value far exceeds the corresponding chi-squared value with 8 degrees of freedom at any reasonable level of significance. Thus, the test rejects the traditional gravity model in favor of an attractionend choice model.

As can be observed from Table 1, the variables in the final specification include the composite impedance variable, three zonal attributes (retail acreage, other acreage 
and percentage of water area), the zonal spatial structure measure specific to park area, and socio-demographic and other interaction variables. None of the trip-related attributes (number of individuals participating in the recreational pursuit, travel mode choice, departure time of trip, etc.) were statistically significant.

The parameter signs on the variables are in the expected direction. A larger impedance between the production zone and a candidate attraction-end zone makes it less likely that the candidate attraction-end zone will be chosen for the recreational trip.

Among the zonal attributes, the coefficient on the composite size variable is significantly smaller than one, indicating that there are unobserved zonal attributes affecting the utility of elemental recreational destinations within the zone (see Daly, [20]). Between the retail acreage and non-retail acreage size variables characterizing the composite size measure, the parameter on the former is larger than that on the latter (the coefficient on retail acreage is constrained to one for identification). However, the average non-retail acreage is about 64 times the average retail acreage. After controlling for the magnitude difference, the results imply that 1 square mile of non-retail acreage (including park space and water area) is equivalent to about 3 square miles of retail acreage in terms of zonal size representation. Effectively, then, retail area contributes less to the attractiveness of a zone compared to non-retail area. The only non-size zonal variable found to influence zonal attractiveness is the water area in the zone as a percentage of total zonal area. The result implies that while water area increases attractiveness of a zone through the size measure (since water area is included within non-retail area), zones with a higher percentage of water area are less preferred to those with a better mix of recreational facilities. 
The spatial structure measure specific to parkland is highly significant in its effect on attraction-end choice. The positive parameter on this measure reflects the presence of agglomeration forces; that is, zones in close proximity to other park-related recreational opportunities have a higher utility than zones in spatial isolation. This may be a reflection of the preference for large parks extending across several spatially contiguous zones, which manifests itself in the form of an agglomeration effect.

The empirical results indicate significant socio-demographic and other interactions, especially with the composite impedance variable. The sensitivity to impedance is higher for older individuals, for individuals with children in their households, and for individuals participating alone in recreational activities. These results are quite intuitive. Older individuals might prefer less travel because of physical challenges and constraints; individuals with children may prefer closer recreational destinations because of biological and related considerations of children; individuals traveling alone may have a higher sensitivity to level-of-service because travel time is likely to be more onerous compared to traveling with others. On the other hand, sensitivity to impedance is lower for individuals with many cars in the household and for lower income households (less than an annual income of $\$ 30,000)$. The former effect might reflect a lack of car allocationrelated constraints among individuals of a household, so that recreational pursuits of individual in households with several cars are not time-constrained. The explanation for the latter effect may be two-fold. First, individuals in low-income households may be willing to travel farther to explore inexpensive locations for recreational pursuits. Second, low-income households may be located in areas that are not near recreational facilities. The final socio-demographic variable represents the differential sensitivity of workers 
and non-workers to the spatial measure for parkland. Specifically, the positive sign on the interaction of employment status and the parks and spatial measure suggests that the agglomeration effect characterizing recreational attraction-end choice is tempered for workers compared to non-workers (note that the agglomeration effect still persists for workers, since the overall spatial effect for workers is the sum of the spatial measure for parkland and the interaction term). The smaller agglomeration effect for workers may reflect a time trade-off; workers may visit near-by, small, parks rather than large parks spanning multiple zones that may be farther away from their home.

A note regarding the specification of the socio-demographic variables is in order here. In addition to the linear interaction effect of age with level-of-service presented in Table 1, we also explored non-linear spline effects of age; however, these non-linear effects did not improve data fit and were also difficult to interpret. An approach that assigned people to discrete categories based on age was also tested, but the linear interaction specification of age was superior in terms of data fit. For income, however, the best result was obtained by using a discrete categorization.

\section{CONCLUSIONS}

This paper presents an attraction-end choice model for urban recreational trips. The focus on recreational trips is motivated by the growing number of such trips in urban areas, and also because such trips tend to be longer than trips for other purposes.

The model structure used in the analysis takes the form of a non-linear-in-parameters multinomial logit model to accommodate multiple size measures characterizing the number of elemental alternatives within each attraction-end zone. A random-sampling 
scheme that selects ten attraction-end zonal alternatives is implemented to address the large number of alternatives in any individual's attraction-end choice set for recreational trips. The model is estimated using data on home-based recreational trips from the 1996 Dallas-Fort Worth activity survey conducted by the North Central Texas Council of Governments (NCTCOG). Important results from our empirical analysis are as follows:

- The level-of-service from the home of the individual to a potential recreational site is an important determinant of whether or not the site will be chosen; individuals prefer locations which are easier to reach and less expensive to travel to.

- Zonal size, characterized by retail space and non-retail space (including park space, water area, and other area), influences the choice of zone for recreational activity; larger zones with more opportunities for recreation are preferred to smaller zones. One unit of non-retail area is about equivalent to three times a unit of retail area in the context of size representation for urban recreational trips.

- Zones with a higher percentage of water area are less preferred to those with a better land-mix of recreational facilities.

- Agglomeration effects dominate in recreational attraction-end choice; specifically, zones that are clustered around other zones with large parkland area are preferred over zones that are relatively isolated.

- Socio-demographics have a very important role to play in recreational attraction-end choice. In particular, older individuals, individuals in households with children, and single-individual households (who comprise a large fraction of individuals participating alone in recreational activities) are likely to choose recreational 
locations that are closer to home. On the other hand, individuals with several cars in their households and low-income individuals tend to travel farther away from home.

The foregoing results have substantial implications for transportation planning, transportation air quality analysis, land-use planning, and demographic modeling, as we discuss next.

\subsection{Transportation Planning}

The empirical analysis indicates significant differences in the decision process underlying recreational location choice based on the socio-demographics of the traveler and her/his household. Recognizing these socio-demographic effects is very important today because of the rapidly changing socio-demographic profile of the United States. For example, the age of the population is increasing, especially in the South and the Midwest United States (Texas State Data Center [22]; U.S. Bureau of Census [23]). Also, single-individual families are on the rise (a recent survey by the University of Chicago indicates that the percentage of traditional nuclear families decreased from 45\% in 1972 to $26 \%$ in 1998; see Austin-American Statesman [24]). The effect of these changes will be to reduce the length and duration of recreational trips, according to our empirical results. From this perspective, socio-demographic changes in the population might alleviate traffic congestion in the context of recreational travel. However, the shorter trips may also imply a displacement of trips from urban freeways to surface streets (such as arterial and collector roads). To the extent that the capacity of surface streets is much lower than freeways, the displacement might add traffic congestion within urban areas. 
Appropriate transportation planning to recognize the increased demands on urban nonfreeway facilities due to recreational travel would, therefore, be important.

The empirical results also indicate the positive influence of number of cars in a household on the duration and length of recreational trips. Earlier studies have indicated that a higher number of cars in a household leads to increased trip-making, more drive alone travel, and the de-coupling of activities from activity chains, all of which contribute to increased traffic congestion in urban areas (see, for example, Agyemang-Duah and Hall [25], and Misra and Bhat [3]). Our study suggests that car ownership also has an impact on the length of trips for recreational purposes. Thus, land-use and transportation policies (such as better land-use mixing, improved transit service, higher car purchase and gas taxes, etc.) which reduce car dependency and increase car costs, and eventually reduce car ownership, constitute one of the most fundamental ways to alleviate trafficcongestion in urban areas.

The model of recreation choice behavior in this paper can also be used to assess the potential impact of transportation control measures (TCMs). For example, the model can be used to evaluate the impact of a congestion pricing strategy on the spatial redistribution of trips. To be sure, the aggregate gravity model can also be used for this purpose as long as the impedance term in the gravity model includes time and cost components. However, the gravity model does not adequately capture the effect of sociodemographics on sensitivity to level-of-service. Thus, it assumes away the existence of demographic variations across different spatial units within a metropolitan region. This can lead to incorrect origin-destination interchanges and, consequently, inaccurate policy analysis. In addition, an advantage of the attraction-end choice formulation of this paper 
is that it is able to assess the impact of TCMs by socio-demographic group (for example, low income earners and the elderly). This is critical in the context of environmental justice considerations in transport policy analysis.

To summarize, the disaggregate recreational choice model can be integrated within the travel demand modeling framework of Metropolitan Planning Organizations for improved forecasting as well as policy analysis.

\subsection{Transportation Air Quality Analysis}

The integration of transportation planning and air quality planning is important for mobile source emissions estimation and for establishing conformity of mobile source emissions to the emissions budgets in State Implementation Plans. The Environmental Protection Agency (EPA) requires the use of the MOBILE emissions factor model for such emissions estimation and conformity analysis for all areas except California, which uses the EMFAC7F model.

The emissions factor models (MOBILE or EMFAC7F) require several trafficrelated inputs, some of which are obtained from travel demand models (for example, speed and vehicle miles of travel (VMT) on links in the network). To the extent that the current paper has formulated a recreational attraction-end choice model that can contribute to improved link speeds and VMT, improved mobile-source emissions forecasting can also be expected. In addition, the emissions models also require certain supplementary inputs, one of which is the vehicle trip duration distribution in the planning region. The emissions factor model uses this information to estimate running loss emissions. Running loss emissions are evaporative emissions that have escaped from 
a vehicle while the engine is operating (from spots where the vehicle's evaporative/purge system has become inoperative). Due to greater heating of the engine fuel and evaporative system on longer trips, running loss emissions continually increase as a function of trip duration until the emissions reach a plateau at a trip duration of about 50 to 60 minutes. The model in this paper can be used to forecast recreational site choices due to socio-demographic, land-use, and network level-of-service changes, which may then be translated to an effective trip time distribution for recreational travel using the level-of-service information.

It is clear from above that accommodating socio-demographic interactions with levelof-service and land-use patterns in recreational destination choice is important not only for transport planning, but also for transportation-air quality modeling.

\subsection{Land-Use Planning}

In the section on transportation planning above, we discussed the travel impacts of the rapidly changing socio-demographic characteristics of the U.S. population. However, one can also view the empirical results from the perspective of the mobility needs of sociodemographic groups; this will facilitate land-use planning that is consistent with the changing recreational needs of the population. For instance, older individuals are very sensitive to travel level-of-service. Thus, targeted investments to provide more opportunities for recreational pursuits, especially in retirement communities, should be a goal of land-use planning in the next decade. The focus should be on pedestrian- and transit-friendly recreational developments that are inexpensive to travel to. 
Similarly, the positive coefficient on the low-income interaction variable with levelof-service may suggest the absence of adequate recreational facilities in and around lowincome neighborhoods. Targeting such neighborhoods for the construction of recreational facilities, or for information campaigns on currently available facilities in the neighborhood, would be useful for two reasons. First, low-income individuals may travel less for recreational pursuits, thereby reducing vehicle miles of travel. Second, building relatively inexpensive and mixed recreation/child care facilities might encourage more recreational activity participation, which may have far-reaching health and other societal benefits.

Another empirical finding from our analysis is that workers have less of a preference for large parks compared to near-by parks, even if these close-to-home parks are small. Therefore, neighborhoods with a high percentage of workers, or a growing number of workers, should be designed to provide well-dispersed recreational opportunities. This is of particular relevance since the fraction of workers in the overall population is increasing.

Collectively, the results show a need for adequate distribution of recreational facilities in residential areas. Areas with a poor park system or substandard recreational facilities appear to be contributing to extra vehicle miles because people are traveling farther to reach better facilities. Also, the changing socio-demographic profile of the population requires careful land-use planning to locate recreational facilities. Finally, in an era of urban renewal and downtown restoration projects, recreation should not be overlooked as a trip attractor. 


\subsection{Demographic Modeling}

A clear finding from our empirical analysis is the effect of socio-demographics on recreational location choice. Of course, the application of the model in forecasting requires spatial-temporal forecasts of household structure, car ownership, and employment arrangements, in addition to the age and income forecasts that are commonly used by MPOs. This need for more extensive socio-demographic forecasting is sometimes inappropriately perceived as a "weakness" of disaggregate travel models such as the one estimated in the current paper. The more appropriate conclusion to be drawn from the results is that socio-demographic forecasting must be given substantially more attention today, both because of the changing face of the population as well as because of the substantial impacts that these changes will have on future travel patterns (see also Deakin, Harvey, Skabardonis, Inc. [8] for the importance of including sociodemographic and lifestyle issues in forecasting travel behavior). In this regard, microsimulation approaches, based on transition probabilities or underlying econometric models, have been receiving substantial attention in the past decade (see, for example, Goulias and Kitamura [26]; Bhat and Koppelman [27]; and Miller and Salvini [28]).

\section{ACKNOWLEDGEMENTS}

This research was funded by the U.S. Department of Transportation through the Southwest Region University Transportation Center. The second author would also like to acknowledge funding support from the Texas Department of Transportation and the National Science Foundation grants DMS 9208758 and DMS 9313013 to the National Institute of Statistical Sciences (NISS). We are grateful to the North Central Texas 
Council of Governments Staff for providing the data and assisting with data-related issues. Finally, thanks are due to Lisa Weyant for her typesetting and formatting of this document. 


\section{REFERENCES}

1. Steed, J., and C.R. Bhat. On Modeling Departure Time Choice for Home-Based Social/Recreational and Shopping Trips. Forthcoming, Transportation Research Record, 2000.

2. U.S. Department of Commerce. Total Disposable Personal Income by State and Region, 1969-95. Bureau of Economic Analysis. http://www.bea.doc.gov/bea/regional/articles/1096rem/tab3-1.htm

3. Misra, R. and C.R. Bhat. A Descriptive Analysis of Non-Worker Daily Activity Travel Patterns. Forthcoming, Transportation Research Record, 2000.

4. Handy, S. L. Regional Versus Local Accessibility: Neo-Traditional Development and its Implications for Non-Work Travel. Built Environment, Vol.18, No. 4, 1992 , pp. 253-267.

5. Hunt, J. D. A Stated Preference Examination of Time of Travel for a Recreational Trip. Journal of Advanced Transportation, 1996.

6. Bhat, C. R. Accommodating Flexible Substitution Patterns in Multi-dimensional Choice Modeling: Formulation and Application to Travel Mode and Departure Time Choice. Transportation Research, Vol. 32B, No. 9, 1998, pp. 455-466.

7. Kumar, A. and D. Levinson. Temporal Variations on Allocation of Time.

Transportation Research Record, Vol. 1493, 1995, pp. 118-127.

8. Deakin, Harvey, Skabardonis, Inc. Manual of Regional Transportation Modeling Practice for Air Quality Analysis. The National Association of Regional Councils, Washington, D.C., 1993. 
9. Williams, S. Outdoor Recreation and the Urban Environment. Routledge, New York, 1995.

10. Timmermans, H. J. P. A Stated Choice Model of Sequential Mode and Destination Choice Behavior for Shopping Trips. Environment and Planning Vol. 28A, 1996, pp.173-184.

11. Miller, E. and M. O'Kelly. Estimating Shopping Destination Choice Models From Travel Diary Data. Professional Geographer, Vol. 35, No. 4, 1983, pp. 440-449.

12. Bhat, C.R., Govindarajan, A., and V. Pulugurta. Disaggregate Attraction-End Choice Modeling. Transportation Research Record, Vol. 1645, 1998, pp. 60-68.

13. Koppelman, F. S. and J. R. Hauser. Destination Choice Behavior for Non-Grocery Shopping Trips. Transportation Research Record, Vol. 673, 1978, pp. 157-165.

14. Eash, R. Destination and Mode Choice Models for Nonmotorized Travel.

Transportation Research Record, Vol. 1674, 1999, pp.1-8.

15. Train, K. Recreation Demand Models with Taste Differences Over People. Land Economics, Vol. 74, No. 2, 1998, pp. 230-239.

16. Morey, E., Shaw, W. D., and R. Rowe. A Discrete-Choice Model of Recreational Participation, Site Choice, and Activity Valuation When Complete Trip Data Are Not Available. Journal of Environmental Economics and Management, Vol. 20, 1991, pp.181-201.

17. Yai, T., Yamada, H., and N. Okamoto. Nationwide Recreational Travel Survey in Japan: Outline and Modeling Applicability. Transportation Research Record, Vol. 1493, 1995, pp. 29-38. 
18. McFadden, D. Modeling the Choice of Residential Location. Spatial Interaction Theory and Planning Models, Edited by Karlquist, A., Lundquist, L., Snickbars, F., and J.W. Weibull. North Holland, Amsterdam, 1978, pp. 75-96.

19. Ben-Akiva, M., Gunn, G.H., and L. Silman. Disaggregate Trip Distribution Models. Proceedings of the Japanese Society of Civil Engineers (JSCE), 1984.

20. Daly, A. Estimating Choice Models Containing Attraction Variables. Transportation Research, Vol. 16B, 1982, pp. 5-15.

21. Fotheringham, A. Some Theoretical Aspects of Destination Choice and Their Relevance to Production-Constrained Gravity Models. Environment and Planning, Vol. 15A, 1983, pp. 1121-1132.

22. Texas State Data Center \& The Center for Demographic and Socioeconomic Research and Education. Projections of the Population of Texas and Counties in Texas by Age, Sex and Race/Ethnicity for 1990-2030. College Station, Texas A\&M, 2000. http://txsdc.tamu.edu/cgi-bin/prjctn2000.cgi

23. U.S. Bureau of the Census. Population Projections for States by Age, Sex, Race, and Hispanic Origin: 1995 to 2025. Population Projections Branch, 1996. http://www.census.gov/population/www/projections/ppl47.html

24. Austin-American Statesman. Poll: Only a quarter of families are 'traditional'. November $26^{\text {th }}, 1999$, p. A31.

25. Agyemang-Duah, K. and F.L. Hall. Spatial Transferability of an Ordered-Response Model of Trip Generation. Transportation Research, Vol. 31A, 1997, pp. 389-402.

26. Goulias, K.G. and R. Kitamura. Travel Demand Forecasting with Dynamic Microsimulation. Transportation Research Record, Vol. 1357, 1992, pp. 8-17. 
27. Bhat, C.R. and F.S. Koppelman. An Endogenous Switching Simultaneous Equation System of Employment, Income and Car Ownership. Transportation Research, Vol. 27A, 1993, pp. 447-459.

28. Miller, E.J. and P.A. Salvini. Activity-Based Travel Behavior Modeling in a Microsimulation Framework. Invited resource paper, forthcoming in the proceedings of the Eighth Meeting of the International Association for Travel Behaviour Research, Austin, Texas, 2000. 

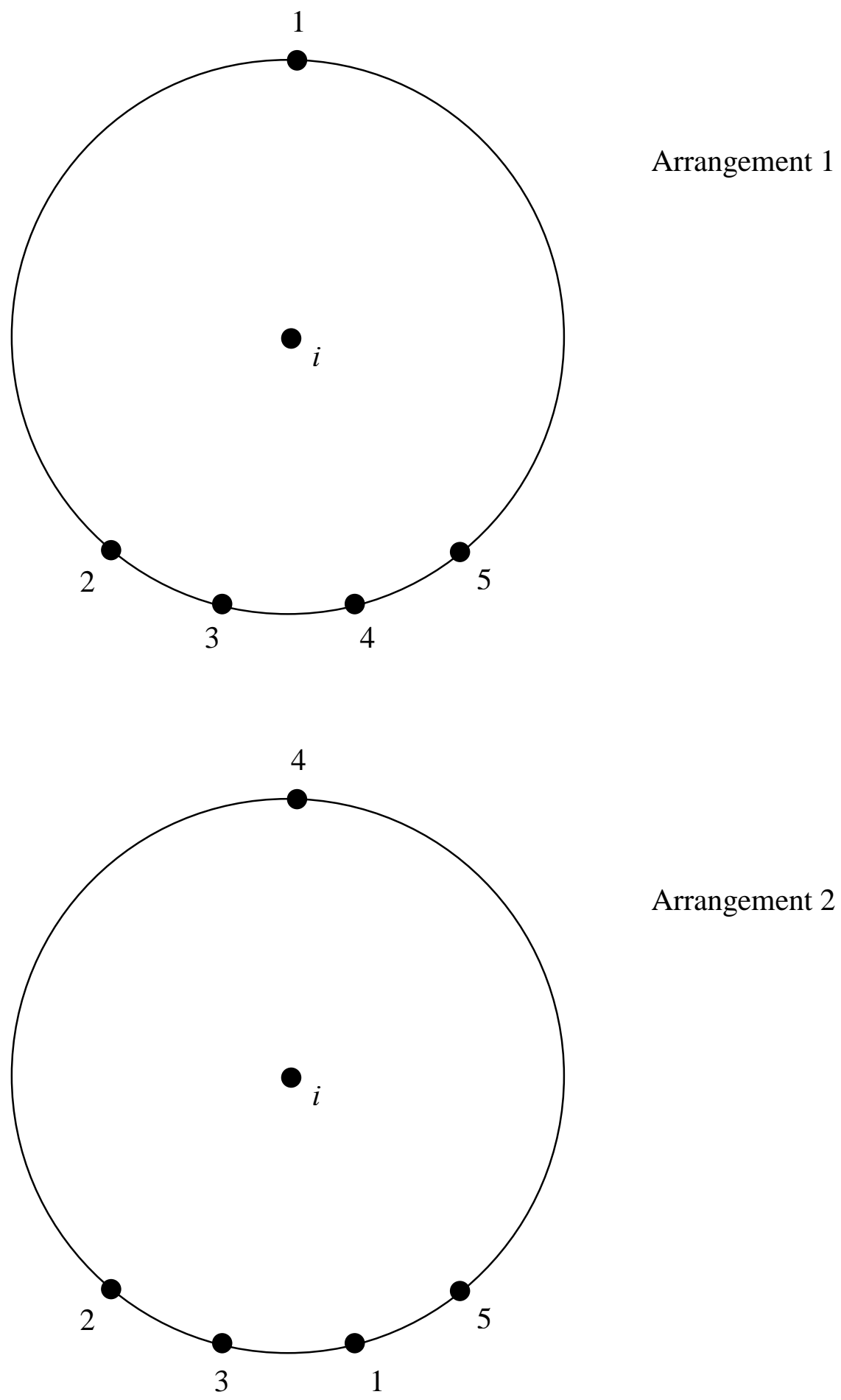

FIGURE 1 Example Spatial Arrangement of Zones.

Source: Fotheringham [21] 
TABLE 1 Home-Based Recreational Attraction-End Choice Model

\begin{tabular}{|c|c|c|}
\hline Variable & Parameter & t-stat. \\
\hline Log of composite impedance ${ }^{a}$ & -1.965 & -5.56 \\
\hline \multicolumn{3}{|l|}{ Zonal attributes } \\
\hline Log of Composite zonal size measure & 0.496 & 8.79 \\
\hline Retail acreage $^{\mathrm{b}}$ & 1.000 & -- \\
\hline Non-retail acreage & 0.045 & 2.13 \\
\hline Percentage of water area & -3.598 & -3.19 \\
\hline Zonal spatial measure specific to Parkland & 1.191 & 5.05 \\
\hline \multicolumn{3}{|l|}{$\begin{array}{l}\text { Socio-demographic and other interactions } \\
\text { with log of composite impedance }\end{array}$} \\
\hline Age & -1.753 & -3.21 \\
\hline Presence of children between 5-21 years in household & -0.689 & -3.41 \\
\hline Participating alone in recreation & -0.391 & -2.29 \\
\hline Number of cars in household & 2.988 & 3.33 \\
\hline Low income household $(<\$ 30,000$ per year $)$ & 0.399 & 1.71 \\
\hline \multicolumn{3}{|l|}{ with spatial measure specific to Parkland } \\
\hline Worker & -0.727 & -2.24 \\
\hline Number of observations & \multicolumn{2}{|c|}{7770} \\
\hline Log-likelihood at zero & \multicolumn{2}{|c|}{-1789.0} \\
\hline Log-likelihood at convergence & \multicolumn{2}{|c|}{-876.7} \\
\hline
\end{tabular}

${ }^{\text {a }}$ The unit of the composite impedance variable is equivalent highway in-vehicle travel time (in minutes).

b The coefficient on this variable is constrained to one for identification purposes. 


\section{LIST OF FIGURES AND TABLES}

Figure 1. Example spatial arrangement of zones.

Table 1. Home-based recreational attraction-end choice model. 